\title{
Effects of Telerehabilitation on Occupational Therapy Services in the Coronavirus Disease 2019 Era: An Umbrella and Mapping Review with Meta- Meta-Analysis
}

\section{Sara Mohammad Alageel ( $\sim$ SARAALAQEEL@HOTMAIL.COM )}

King Saud University College of Applied Medical Sciences https://orcid.org/0000-0001-5406-6679

\section{Research Article}

Keywords: Telerehabilitation, Occupational Therapy, Telehealth

Posted Date: April 20th, 2021

DOl: https://doi.org/10.21203/rs.3.rs-427787/v1

License: (9) This work is licensed under a Creative Commons Attribution 4.0 International License. Read Full License 


\section{Abstract}

\section{Purpose}

Telerehabilitation (TR) is a medical option that should be embraced in contemporary society to curb the spread of coronavirus. An umbrella along with mapping review based on a meta-meta-analysis (MMA) has recently been conducted using available scientific revelations to establish whether TR could be a critical option for traditional rehabilitation systems in occupational therapy practices [1].

\section{Methods}

A systematic review of reviews along with previous and current studies on the objectives and systematic evidence based on an MMA and visual maps was conducted. A systematic search was then initiated in the Google Scholar, MEDLINE (PubMed), and Cochrane Database of Systematic Reviews (CDSR). Accordingly, two independent reviewers scrutinized and examined all obtained data and simultaneously analysed the authenticity of the reviews included while evaluating the bias risks using ROBIS.

\section{Results}

Twenty-five articles that met the inclusion thresholds were selected and grouped based on the conditions of the patients on rehabilitation, which constituted musculoskeletal, cardiorespiratory, and neurological conditions. The MMA linked to occupational functioning between normal care rehabilitation and TR failed to indicate a statistical difference among patients with musculoskeletal and cardiorespiratory conditions [2]. The MMA showed statistically significant results among patients with neurological conditions but with negligible impacts in six reviews on TR. The standardized mean difference was 0.18 with a 95-confidence interval of 0.03-0.34.

\section{Conclusion}

These results suggest that TR provides admirable results that in many ways can be compared with faceto-face rehabilitation processes.

\section{Impact}

TR has the advantage of reducing costs that work along with its minimal interruptions on a patient's contemporary interactions, suggesting that it helps current medical setups when society requires minimal interactions to curb the spread of coronavirus.

\section{Full Text}

This preprint is available for download as a PDF.

\section{Figures}




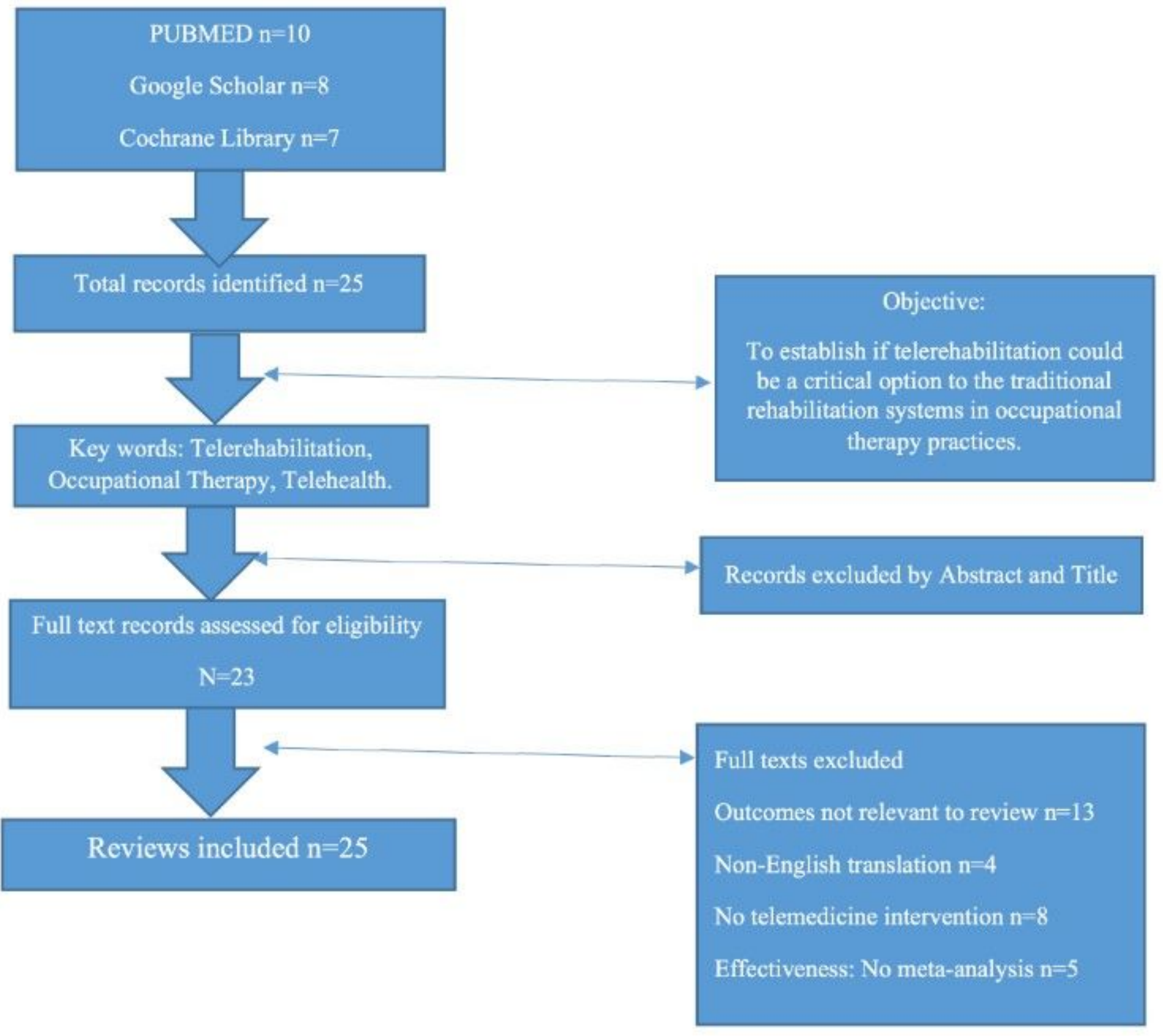

Figure 1

Prisma Diagram Showing the Results 